\title{
Love, Trust, and Evolution: Nurturance/Love and Trust as Two Independent Attachment Systems Underlying Intimate Relationships
}

\author{
Kevin MacDonald1', Emily Anne Patch ${ }^{2}$, Aurelio José Figueredo² \\ ${ }^{1}$ Department of Psychology, California State University, Long Beach, USA \\ ${ }^{2}$ Graduate Program in Ethology and Evolutionary Psychology, Department of Psychology, University of Arizona, \\ Tuscon, USA \\ Email: kevin.macdonald@csulb.edu,epatch@email.arizona.edu,ajf@u.arizona.edu
}

Received 7 December 2015; accepted 20 February 2016; published 23 February 2016

Copyright (C) 2016 by authors and Scientific Research Publishing Inc.

This work is licensed under the Creative Commons Attribution International License (CC BY).

http://creativecommons.org/licenses/by/4.0/

(c) (i) Open Access

\begin{abstract}
Research has indicated two dimensions of attachment, Avoidance and Anxiety. We show that Avoidance is better conceptualized as Nurturance/Love within an evolved systems perspective on personality, and that the Anxiety dimension in infancy measures trust in the face of threat based on experience. These two dimensions have important differences, including different evolutionary functions and phylogeny, as well as different emotions, brain mechanisms, and patterns of sex differences and heritability. We used two versions of the Experiences in Close Relationships Survey yielding measures of Anxiety and Avoidance, and the Interpersonal Adjective Scale-Revised-Big 5, the latter chosen because it measures Nurturance/Love in a manner consistent with an evolutionary perspective on close relationships. 635 subjects participated in the study. Results supported the hypotheses of a strong negative association between Nurturance/Love and Avoidance as measured by the ECR and no association between Nurturance/Love and Anxiety as measured by the ECR.
\end{abstract}

\section{Keywords}

Attachment, Love, Trust, Life History Theory, Evolutionary Personality Psychology

\section{Theoretical Introduction}

Building on original categorical conceptualizations of attachment, research in adult attachment has offered support for a dimensional model. Bartholomew (1990) proposed two dimensions, a model of self (or attachment an-

How to cite this paper: MacDonald, K., Patch, E. A., \& Figueredo, A. J. (2016). Love, Trust, and Evolution: Nurturance/Love and Trust as Two Independent Attachment Systems Underlying Intimate Relationships. Psychology, 7, 238-253.

http://dx.doi.org/10.4236/psych.2016.72026 
xiety) and model of partner (or attachment avoidance) as the factors. Later research by Shaver and colleagues (Brennan, Clark, \& Shaver, 1998) using the Experiences in Close Relationships Inventory (ECR) indicated two dimensions labeled Avoidance and Anxiety. Summarizing this consensus, Del Giudice (2009) notes support for two robust dimensions of romantic attachment, avoidance and anxiety.

The main purpose of this paper is to integrate research on attachment with research on the Love/Nurturance dimension of the Interpersonal Circle by showing that Avoidance is better conceptualized as Nurturance/Love within an evolved systems perspective on personality, and that such a reinterpretation provides a straightforward way of interpreting age changes in patterns of sex differences and heritability of attachment. Further, the anxiety dimension found in attachment research is conceptualized as trust in the face of threat, as influenced by experiences with the mother in situations pulling for fear as well as individual differences in the personality system of emotionality/neuroticism.

An advantage of the dimensional approach is that it can be readily linked to personality psychology. Noftle and Shaver's (2006) review indicated moderate negative associations between measures of attachment security and neuroticism, and moderately positive associations between attachment security and agreeableness and extraversion. In particular, they presented data indicating moderate associations between ECR Anxiety and a Big Five measure of neuroticism $(r=0.42 ; b=0.40)$, and moderately negative associations between ECR Avoidance and Big Five measures of Extraversion $(r=-0.21 ; b=-0.11)$ and Agreeableness $(r=-0.22 ; b=$ -0.18 ). A second study using the NEO-PI-R replicated the findings linking Neuroticism and ECR-Anxiety ( $r=$ $0.52 ; b=-0.53$ ) and the findings of a moderate negative correlation between Extraversion and ECR-Avoidance $(r=-0.26 ; b=-0.17)$. However, in the second study there was no significant correlation between Agreeableness and ECR-Avoidance.

These results show intriguing links between personality and attachment style. The present paper explores the relationship between attachment style and personality from an Evolutionary Systems Perspective on attachment and personality, as informed by Life History Theory. We attempt to demonstrate that different dimensions of personality, specifically Nurturance/Love and Dominance/Power rather than Agreeableness and Extraversion, should be used when examining attachment style, because these linkages are more strongly grounded in evolutionary theory. It is important to note, however, that neither the Evolved Systems Perspective nor Life History Theory expects a 1:1 mapping of evolved psychological mechanisms with the common factors (such as Extraversion and Agreeableness) that have emerged from exploratory factor analyses (EFA) of personality items. There are several reasons for this, one of which is that factor rotations in EFA can be somewhat arbitrary in the absence of strong theory. As Trapnell and Wiggins (1990) pointed out, the difference amounts to a rotational difference between two different ways of conceptualizing the same interpersonal space.

\subsection{Evolutionary Systems Perspective}

The Evolutionary Systems Perspective on personality proposes that personality systems are psychological adaptations designed for specific functions in what Bowlby $(1969,1982)$ termed the Environment of Evolutionary Adaptedness - the environment that a species evolved in that presented a set of species-specific problems that were solved by the set of human adaptations. This perspective (MacDonald, 1995, 2008, 2012) expects to find homologous (i.e., inherited from a common ancestor) systems that serve similar adaptive functions, and it expects that these systems will be organized within the brain as discrete neurophysiological systems. For example, among even the most primitive mammals, there must be systems that encourage exploring the environment to obtain resources, prototypically foraging and mate attraction systems. Thus, Panksepp (1998) has argued that the mammalian brain contains a "foraging/exploration/investigation/curiosity/interest/expectancy/SEEKING" system (p. 145). The behavioral approach personality systems (BAS) evolved from systems designed to motivate approach toward sources of reward (e.g., mating, food, dominance, control of territory) that occurred as enduring and recurrent features of the environments in which animals or humans evolved.

Important for the present paper is an evolutionary understanding of Nurturance/Love as an adaptive system. Mammalian females give birth to and suckle their young. This has led to a host of adaptations for mothering, an outgrowth of which are pair-bonding mechanisms present also in males (MacDonald, 1992). For species that develop pair bonds and other types of close relationships involving nurturance and empathy, one expects the evolution of a system designed to make such relationships psychologically rewarding. Nurturance/Love therefore is conceptualized as a mechanism for cementing relationships of love and empathy among adults and children, prototypically within the family. 
The empirical basis for proposing such a system can be found in studies of Nurturance/Love, the second factor emerging from research on the Interpersonal Circle (Kiesler, 1983). Nurturance/Love is associated with relationships of intimacy and other long-term relationships, especially family relationships involving reciprocity and transfer of resources to others (e. g., nurturing children, empathic concern, working in the helping professions; Kiesler, 1983; Trapnell \& Wiggins, 1990). Recently, models of temperament have included a dimension of affiliativeness designed to make temperament instruments more congruent with measures of adult personality (Rothbart, 1994; Evans \& Rothbart, 2007). Affiliativeness involves warmth, love, closeness, empathic concern and a desire to nurture others also characteristic of Nurturance/Love.

The physiological basis of pair bonding involves specific brain regions (Bartels \& Zeki, 2004; Burkett et al., 2011) and the hormones oxytocin and vasopressin as well as opiates and dopamine (Atzil et al., 2011; Burkett et al., 2011; Insel et al., 1998; Panksepp, 1998; Turner et al., 1999). These mechanisms are associated with subjective feelings of pleasure. For example, in prairie voles (Microtus ochrogaster), a monogamous species with paternal involvement in provisioning the young, oxytocin receptors (Insel et al., 1998) and opioid receptors (Burkett et al., 2011) are found in brain regions associated with reward and with pair bonding, supporting the proposal that pair bonding is a reward-based system that functions to facilitate intimate family relationships and parental investment (MacDonald, 1992). The stimuli that activate this system act as natural clues (in the sense of Bowlby, 1969) for pleasurable affective response. Intimate relationships and the nurturance of the objects of affection are pleasurable, and such relationships are sought out by those sensitive to the reward value of this stimulation. Highly pleasurable interactions are characteristic of parent-child relationships labeled as warm and affectionate - the dance of affective modulation whose goal is "to be with and enjoy someone else" (Stern, 1977: p. 71) or to "maintain a relational state that is evaluated positively" (Tronick, 1982: p. 3).

\subsection{Life History Strategy Theory}

The Life History Theory perspective also supports the notion that species will have adaptations designed to support life in their ecological context. An organism's specific adaptations will depend on a variety of extrinsic and intrinsic threats to its survival, and they will allocate resources according to the absence or presence of these threats. The theory predicts that an organism that develops in a harsh, unpredictable environment, where risk of mortality is high, will invest bioenergic and material resources differently than an organism that develops in a stable, predictable environment (Ellis et al., 2009). For example, an organism that develops in a dangerous environment where risk of predation is high will allocate more resources to reproductive effort; passing on its genes, rather than investing in its own growth, becomes the more important goal because its future is largely uncertain. An animal that invests more resources in reproductive effort is referred to as $r$-selected or "fast", on the Life History continuum. Conversely, if an animal develops in a safe, resource-rich environment, it will first allot energy to its own growth or somatic effort to improve its competitive ability in environments that foster higher levels of both intraspecific and interspecific competition. Organisms that primarily invest their energy in their own somatic effort are referred to K-selected or "slow".

There are various indicators of an organism's life history strategy, including levels of parental investment, onset of puberty, age of first sexual activity, and age of first birth, to mention a few. For example, elephants, which are a $K$-selected species, heavily invest in their offspring, even before their birth. The typical gestation period for an elephant is between 550 - 670 days, depending on the species, which eventually leads to the birth of the largest land mammal on earth. After birth, they can lactate for up to 36 months (McCullagh \& Widdowson, 1970). An elephant's extremely large size reduces its risk of predation, increases somatic effort, and delays reproduction, which are all salient indicators of a latent life history construct. This development is in stark contrast to that of the rat, an $r$-selected species. A rat reaches sexual maturity at around 3 months of age, and may produce up to 12 litters a year. Their gestation period is decidedly shorter, lasting only 21 - 26 days. Life History Strategy may produce variation between species and also within species; this paper focuses on within species variation.

Using LHS as a framework allows one to make predictions about an individual's personality traits and attachment style. Slow life history strategists are predicted to be more mutualistic, agreeable, and cooperative than their $r$-selected counterparts. $K$-selected individuals invest in the future and in their relationships, because their experiential history and environmental cues inform them that the environment is stable and their altruistic relationships will prove mutually beneficial. Thus secure attachments and warm, affectionate parent-child relationships have been found to be associated with a high-investment style of parenting characterized by later sexual 
maturation, stable pair bonding, and warm, reciprocally rewarding, non-exploitative interpersonal relationships (Belsky, Steinberg, \& Draper, 1991). We would also expect $K$-selected individuals to be high on Nurturance/ Love given the importance of Nurturance/Love for pair bonding and investment in children.

On the other hand, individuals with fast life history strategies are predicted to be more aggressive, have more antisocial personality traits, and generally display more deviant behavior. A successful fast life history strategist would not want to invest in long term relationships, when the chance of those long term relationships ending prematurely is high.

An evolutionary perspective expects that each personality system will be responsive to particular environmental contexts, and as such we can make additional predictions. For example we would predict that the Nurturance/Love system is activated by close relationships and family contexts, while the Dominance/Power system is activated by contexts of social competition. It also proposes that different personality systems will have mutually inhibitory connections with each other within individuals, leading at times to psychological ambivalence when more than one system is activated (MacDonald, 2005).

\subsection{Sex Differences in Nurturance/Love and Dominance/Power}

If indeed the main evolutionary impetus for the development of the human affectional system is the need for high-investment parenting (see above), females are expected to have a greater elaboration of mechanisms related to parental investment than males. The evolutionary theory of sex implies that females are expected to be highly discriminating maters compared to males and more committed to long-term relationships of nurturance and affection because cues of nurturance and love in males are expected to be highly valued by females seeking paternal investment.

There are robust sex differences (higher in females) on the IAS-R-B5 LOV scale which measures the Nurturance/Love dimension of the Interpersonal Circle (Trapnell \& Wiggins, 1990). This dimension involves the tendency to provide aid for those needing help, including children and people who are ill (Wiggins \& Broughton, 1985), and would therefore be expected to be associated with high-investment childrearing. This dimension is strongly associated with measures of femininity, and is associated with warm, empathic personal relationships and dependence (Wiggins \& Broughton, 1985).

Sex differences in such behavior and emotions related to Nurturance/Love are prominent beginning in childhood (reviewed in Geary, 2010: pp. 332-334). Girls are more prone to engage in intimate, confiding relationships than boys throughout development (Berndt, 1986; Buhrmester \& Furman, 1987; Douvan \& Adelson, 1966). Females also tend to place generally greater emphasis on love and personal intimacy in sexual relationships than males do (e.g., Buss \& Schmitt, 1993; Douvan \& Adelson, 1966). Females are more empathic and desire higher intimacy in relationships (Lang-Takoc \& Osterweil, 1992), and both sexes perceive friendships with women as closer, richer, more intimate, more empathic, and more therapeutic (e.g., Wright \& Scanlon, 1991). Females exposed prenatally to testosterone-like hormones show reduced empathy (Mathews et al., 2009), and testosterone measured in amniotic fluid is negatively correlated with empathy in both boys and girls (Chapman et al., 2006). Developmentally, sex differences related to intimacy peak during the reproductive years (Turner, 1981), a finding that is compatible with the present perspective that sex differences in intimacy are related to reproductive behavior.

As noted above, Noftle and Shaver's (2006) review indicated moderately positive associations between attachment security and agreeableness and extraversion. However, the hypothesis here is that an evolutionary perspective is much more compatible with using the dimensions revealed by research on the Interpersonal Circle-Nurturance/Love and Dominance/Power rather than Extraversion and Agreeableness used in standard measurements of the Five Factor Model (MacDonald, 1995, 1999b, 2012). This procedure is expected to yield stronger results. Nurturance/Love and Dominance/Power function better as the primary axes of interpersonal space because this conceptualization maximizes theoretically important sex and age differences, and is thus likely to have been the focus of sexual selection. There is little evidence for mean age changes in Extraversion (McCrae \& Costa, 1990; McCrae et al., 2002), while the age changes in Dominance/Power are well known; the "young male syndrome" describes the pattern in which sensation seeking, impulsivity, and aggression peak in young adulthood, exactly at the time when young males must compete for mates and establish themselves in the dominance hierarchy (Wilson \& Daly, 1985).

Sex differences in Extraversion are relatively modest and actually favor females (McCrae et al., 2002; Srivastava, John, Gosling, \& Potter, 2003). This is because Extraversion scales contain items that are related to 
warmth and affiliation — traits that favor females_-as well as items related to dominance and venturesomenesstraits that favor males. Sex differences in Extraversion are therefore diminished or non-existent (see discussion in Lucas, Deiner, Grob, Suh, \& Shao, 2000). From an evolutionary perspective, the concept of a trait consisting of warmth and affiliation does not fit well with a trait consisting of dominance, sensation seeking, and exploratory behavior. As a result, there are opposite patterns of sex differences within the facets of Extraversion in the NEO-PI-R. Given that different Extraversion scales have different loadings of dominance/venturesome items and warmth/affiliation items, findings on sex differences vary from study to study (Costa, Terracciano, \& McCrae, 2001).

Whereas Extraversion taps traits that have different patterns of sex differences, this is not the case with Agreeableness where females are reliably higher. Costa, Terracciano, and McCrae (2001) note that this Five Factor Model trait is a combination of low Dominance/Power and high Nurturance/Love from the Interpersonal Circle. Because both of these traits are more characteristic of females, females consistently score higher on Agreeableness both at the broad factor level and the facet level.

Contrasting with the results for Extraversion, there are robust sex differences in Dominance/Power (as measured by the Interpersonal Circle) (Kiesler, 1983; Trapnell \& Wiggins, 1990). Evolutionary theory predicts that in species with sex-differentiated patterns of parental investment, the sex with the lower level of parental investment (typically the males) is expected to pursue a more high-risk strategy compared with females, including being prone to risk taking, physical aggression, reward seeking, and being less sensitive to cues of punishment—a correlated suite of traits often referred to as the Behavioral Approach System (BAS) (e.g., Panksepp, 1998). These traits are also remarkably similar to traits very commonly expressed by fast life history strategists among human and nonhuman animals.

Generally, males have more to gain by being socially dominant because social status is linked to access to females and reproductive success across a wide range of traditional societies (Betzig, 1986, 2012). Mating is expected to be problematic for males as the low-investment sex, with the result that males must often compete with other males for access to females. Males who compete successfully (i.e., achieve social dominance) have been able to turn their social success into reproductive success. Data on reproductive success in traditional cultures indicate that for men, but not for women, range and variance rise as the economic production of the society intensifies. While there are modest ranges and variances among hunter-gatherer groups, under intensive agriculture emperors were able to father hundreds of children as a result of controlling large numbers of women while the reproductive opportunities of subordinate men were severely compromised.

This evolutionary pattern is well captured by considering the career of Temuchin, the $13^{\text {th }}$-century Mongol leader known to history as Genghis Khan ("Rightful Lord”). By achieving unprecedented military success, he and his male descendants were able to establish large harems of women throughout Asia. Based on modern Y-Chromosome data, Genghis Khan's lineage has 16 million direct male descendants in the modern world (Zerjal et al., 2003). A Mongol female would not have benefited from a similar level of military success because with her limited reproductive potential, she would not have benefited from multiple mates.

Dominance/Power however, is only one facet of the Interpersonal Circle; there are also benefits for some males to be high on Nurturance/Love and invest in a long-term pair bond. As mentioned above, Life History Strategy produces variation between species and also within species, therefore individual males (and females) within a species might exhibit relatively fast or slow traits. Determining whether a male is fast or slow can help researchers make more reliable predictions about a male's future behavior. For example, slow males invest heavily in long-term relationships, and may therefore reap benefits by producing high-quality offspring with greater chances of survival under some circumstances, even if the offspring are relatively few in number compared to fast males. Studies of the Ache, a hunter-gatherer group native to Paraguay, have demonstrated that children who grow up with their fathers present—a marker of a high-investment strategy—have a substantially higher survival rate than those who grow up with no father present; children raised with stepfathers were nearly 45 percent more likely to perish before age 15 (Hurtado \& Hill, 1992; Dixson, 2009: p. 71). In addition, research in the United States and Canada has shown that children, particularly males, are more likely to die due to homicide if there is a stepfather present in the home (indicating the absence of a genetic father; Daly \& Wilson, 1996).

Evidence for the deleterious effects of father absence varies depending on the cultural circumstances. For example, offspring whose fathers invest in mating effort may not have poorer outcomes if their extended family steps in to provide care (Hrdy, 2009). In general, however, slow males should invest more heavily in parental 
effort, while fast males should invest more heavily in mating effort (and potentially Dominance/Power). Depending on their environmental cues, each strategy would predictably result in the optimal outcome for each male in their respective environments.

\subsection{Nurturance/Love and Trust as Two Separate Systems}

The evolutionary systems perspective proposes that Nurturance/Love (based on the emotions of love, sympathy and empathy) and Trust (leading to differences in trust in others under conditions of threat and based on the emotions of anxiety and felt security) are two separate systems underlying close relationships (MacDonald 1992, 1999a, 2005). These systems have different survival functions, different emotions, a different distribution among the Primates, a different pattern of theoretically expected sex differences, as well as theoretically expected differences in heritability (see Table 1).

Mechanisms of attachment that function to keep offspring close to the mother as a means of protection are ubiquitous among primates, including relatively primitive primates, and such mechanisms are common in a wide range of other mammals, including ungulates, carnivores, and rodents (Gubernick, 1981). On the other hand, Nurturance/Love as indicated by pair bonding is far more the exception than the rule in primates and other mammals.

These systems differ in their function as well. Whereas, as noted above, the Nurturance/Love system functions to cement close family relationships and parental investment, attachment security, as Bowlby (1969) proposed, is an adaptation designed to keep the baby close to the mother as a means of protecting the baby from harm. Like the offspring of many other species, human babies respond with fear and anxiety when separated from their mothers between around 6 - 30 months. Thus secure babies show fear, followed by the emotion of felt security when reunited with their attachment objects.

Whereas, as discussed above, the Nuturance/Love system is grounded in reward mechanisms that make close relationships pleasurable, the fundamental mechanism underlying attachment security (trust) is the internal working model (IWM), a cognitively-based schema of self and others based originally on experiences with the mother during fear-inducing situations in infancy and modeled in the laboratory by the Strange Situation Test procedure in which the baby is separated from the mother in an unfamiliar environment. The mothers of securely attached infants are sensitive and responsive to infant cues of distress, resulting in a cognitive schema for the baby that others can be depended on in conditions of personal threat. For securely attached children and adults, the IWM results in felt security and trust: the default interpersonal posture is to trust that others will be there to help them when they are in situations of perceived threat. On the other hand, for insecurely attached children and adults, the IWM results in anxiety about whether others can be trusted: the default interpersonal posture is to be anxious and uncertain that others will be there to help them when they are in situations of perceived threat.

Another difference is that separation anxiety is linked to other fears and phobias, not to deficits in love, affection, and nurturance. Thus Silove and Manicabasagar (2001) found that girls with separation anxiety were at higher risk for developing agoraphobia in late adolescence or adulthood, and Last and Strauss (1989) found that children with separation anxiety are more likely to be diagnosed with generalized anxiety disorder as they get

Table 1. Differences between nurturance/love and trust.

\begin{tabular}{|c|c|c|}
\hline & NURTURANCE/LOVE & TRUST \\
\hline Emotions & Love, sympathy, empathy & Felt security or anxiety \\
\hline Function & $\begin{array}{l}\text { Pair-bonding, nurturance, } \\
\text { investment in children }\end{array}$ & $\begin{array}{l}\text { Protection, proximity maintenance; develop } \\
\text { default trust posture based on experience }\end{array}$ \\
\hline Mechanism & Physiological reward system & $\begin{array}{l}\text { Internal working model, a cognitive schema } \\
\text { based on the behavior of attachment objects }\end{array}$ \\
\hline Environmental input & Parental warmth & Sensitivity and responsiveness \\
\hline Heritable & Yes & No (emotionality/neuroticism may influence indirectly) \\
\hline Five factor model & Yes, Factor II & No \\
\hline Sex differences in infancy & Yes (females > males) & No \\
\hline Distribution among primates & Pair-bonding rare & Very common \\
\hline Patterns among autistic children & No affection, sympathy, empathy & Normal attachments \\
\hline
\end{tabular}


older. These results are to be expected when one considers that anxiety and its opposite, felt security, are the fundamental emotions of what is labeled here as the Trust dimension of attachment. Given the well-established links between Neuroticism and anxiety disorders (Clark, Watson, \& Mineka, 1994), these results are compatible with findings reviewed above and replicated here of a correlation between personality measures of neuroticism and the Trust dimension of attachment.

Further, the distinction between Trust and Nuturance/Love is highlighted by the finding that autistic children typically show attachment behaviors under conditions of perceived threat (Dissanayake \& Crossley, 1996; Rutgers, Bakermans-Kranenburg, van Ijzendoorn, \& Van Berckelaer-Onnes, 2004; van Ijzendoorn et al., 2007) despite gross deficits in reciprocal affectionate social interaction and involvement with parents. These findings suggest that autistic children are deficient in Nurturance/Love but fairly similar to non-autistic children when seeking protection from attachment objects while in distress, indicating comparable levels of attachment Trust.

Critically, there are no statistically significant sex differences in attachment security as measured in the Strange Situation in infancy (Colin, 1996; Del Giudice, 2009), whereas there are sex differences in Nurturance/Love. The standard measure of infant attachment, the Strange Situation Test, assesses differences in baby's response to the attachment figure in a context pulling for fear. It thus emphasizes infants' expectations and responses to mother's behavior in a situation that is designed to result in fear and anxiety rather than emphasize individual differences in tendencies toward love and affection on the part of the baby. Similarly with respect to mother's behavior, the key measures of maternal behavior involve the mother's sensitivity and responsiveness to the baby's distress-measures of reactive behavior that fail to tap pro-active maternal expressions of love and affection toward the infant.

Indeed, maternal sensitivity and responsiveness may be completely unrelated to maternal love and affection in some samples-a finding that is compatible with the present perspective that there are two statistically and evolutionarily independent attachment-related factors, Nurturance/Love and Trust, the latter conceptualized as reflecting individual differences in trust in the face of threat. Ainsworth (1967) found that Ugandan babies were quite securely attached despite the fact that their mothers rarely showed any affection toward them-a phenomenon also noted by LeVine and LeVine (1988) for another African group. In the 1967 study and later, Ainsworth clearly distinguished affection from sensitivity and responsiveness-the latter two qualities defined mainly in terms of how the mother responds to infant signals. Sensitivity and responsivity are thus reactive qualities - exactly the qualities that would be elicited in a situation resulting in fear and anxiety in the baby in the face of perceived threat: A sensitive, responsive mother would quickly detect the baby's distress and respond in a way that would restore the baby's felt security. But that is not at all the same as pro-active behavior of love and affection toward the baby which can be found in many contexts, including feeding and parent-child play. Expressions of love and affection are not necessarily involved in meeting the challenge presented by the threatening context.

The Nurturance/Love system is thus relatively less salient in the Strange Situation Test context: scoring individual differences in affection and warmth in the baby, in the mother, or in the mother-infant relationship is not part of the procedure.

Supporting this, there are well-established sex differences beginning in infancy in empathic concern (reviewed in Geary, 2010: pp. 276-277). Empathic concern is conceptually and psychometrically related to the Nurturance/Love system (warm, empathic personal relationships and dependence; Wiggins \& Broughton, 1985) which is conceptualized here as one of the dimensions of intimate relationships, but which is unmeasured by the Strange Situation procedure. Sex differences favoring girls and women in nurturance and valuing intimate relationships continue throughout life (reviewed above).

On the other hand, sex differences in attachment are sometimes found in middle childhood and adulthood (Del Giudice, 2009). Within the present theoretical perspective, it is noteworthy that attachment measurement instruments designed for use with older children and adults implicitly or explicitly incorporate procedures measuring Nurturance/Love. For example, as discussed in the following section, the Avoidance Scales of the Experience in Close Relationships (ECR and ECR-R) which are used here, contain items which, taken at face value, refer to differences in affection and nurturing tendencies (e.g., "I am very uncomfortable being close to romantic partners"). Moreover, prominent self-report measures cited as measuring attachment in adults are explicitly designed to measure orientation toward romantic relationships (Brennan, Clark, \& Shaver, 1998) in which, as the above review indicates, the Nurturance/Love system plays a major role. Similarly, the Adult Attachment Interview is an open-ended interview procedure that asks subjects to describe their mothers; adjectives such as "lov- 
ing” are discussed in the interview protocols and figure in the scoring procedure (Main \& Goldwyn, 1998).

Further, the Relationships Questionnaire (Bartholomew \& Horowitz, 1991) and the Relationships Scales Questionnaire (Griffin \& Bartholomew, 1994) ask subjects to describe the degree of closeness and intimacy in their relationships (e.g., in the RQ, subjects rate how easily they became "emotionally close" with others and the degree to which they are "comfortable without close emotional relationships"), with separate descriptions related to trust in others ("I am comfortable depending on others and having others depend on me"), the latter considered here as tapping the separate dimension of Trust.

Thus individual differences in the tendency to be loving and nurturing play a prominent role in measures of attachment in older children and adults, but they are not part of the Strange Situation protocols which focus instead on mother's responsiveness to cues of baby's distress in a situation perceived as threatening to the baby. It is thus not surprising that sex differences are not found in the Strange Situation procedure but are found when measured in middle childhood and adulthood.

Finally, another indication that these are separate systems is that studies have found negligible heritabilities in attachment as measured in the Strange Situation in infancy (Bokhorst et al., 2003; see also O'Connor \& Croft, 2001), whereas many studies have shown substantial heritabilities in personality dimensions related to Nurturance/Love (e.g., Bouchard, 1996). Despite the lack of finding evidence for genetic influence in infancy, there is evidence for moderate heritability in measures of adult twins as measured by the Adult Attachment Interview and the Relationships Questionnaire (Brussoni, Lang, Livesley, \& Macbeth, 2000; Torgersen, Grova, \& Sommersted, 2007), both of which, as noted, include assessments of individual differences in Nurturance/Love. Based on the foregoing, this stems from the instruments used on older children and adults incorporating measures of the Nurturance/Love dimension which, as indicated above, is heritable. On the other hand, since the IWM results from the baby tracking the behavior of the mother under conditions of threat, genetic variation is expected to be of much less importance, resulting in findings that genetic variation is not important for explaining the variance in infant attachment in the Strange Situation.

\subsection{The Present Study}

The implication of the above detailed line of reasoning is that when assessing relationships between personality and attachment, an appropriate personality scale would be one that tapped the dimensions of Nurturance/Love and Dominance/Power rather than scales featuring Extraversion and Agreeableness. Additionally, using Life History (LH) Theory as a theoretical framework would allow us to predict which individuals would be more likely to be motivated by love and affection and which would be more likely to display aggressive, rewardseeking, dominant behaviors. These two approaches combined can better help us understand the casual underpinnings of attachment, because both are based on sound theoretical specifications.

We predict that the ECR dimension of Avoidance taps variation that is very similar to the Nurturance/Love dimension on the IAS-R-B5 (reversed) and that, as found in previous studies, ECR Anxiety is most closely linked to Big Five measures of neuroticism. Theoretically, the relationship between neuroticism and ECR Anxiety may stem from the linkage between neuroticism, as measured by the Big Five, and the emotionality system (MacDonald, 1995, 2005, 2012). Emotionality is a behavioral scaling system that allows the organism to scale its responses to current environmental opportunities and threats with positive and negative emotional reactions respectively. This system is well studied at the neurophysiological level, where research implicates catecholamine systems that energize both positive and negative emotion systems (Panksepp, 1998: pp. 109-110, 117). Children high on emotionality would be expected to have very strong emotional reactions to separation from their mothers in the Strange Situation procedure, showing high levels of fear and difficulty in calming down after separation events. Such strong emotional reactions would also be expected to influence their internal working models as babies track the sensitivity and responsiveness of attachment figures and result in higher levels of Anxiety in older children and adults as measured by the ECR.

Additionally, using a life history framework would lead us to predict that measures of life history would be correlated with the Avoidant Attachment dimension of the ECR, but not correlated with the Anxious Attachment dimension. We would predict that Avoidant Attachment would be negatively correlated to measures of Life History speed, typically scored in the slower direction, indicating that individuals who are fast do not invest in long-term pair bonds. They evade any strong emotional attachment, because they are generally more antagonistic, or expect others to also have an antagonistic social schema and socially deviant goals. We would not expect any correlation with the Anxious Attachment subscale of the ECR, however, as this has been demonstrated to be 
related to Neuroticism, which is instead related to the Trust dimension. Neuroticism has the weakest loading on the General Factor of Personality (GFP), which is its main link to LH strategy within the latent hierarchical structure of human LH traits (Figueredo, Woodley of Menie, \& Jacobs, 2015; Figueredo, Patch, \& GómezCeballos, 2015).

The present study therefore tests the following hypotheses:

1) IASR-B5 Nurturance/Love will be negatively associated with ECR Avoidance.

2) IASR-B5 Nurturance/Love will be unrelated to ECR Anxiety.

3) IASR-B5 Neuroticism will be positively associated with ECR Anxiety.

4) Sex differences in IASR-B5 Dominance/Power (males > females) and IASR-B5 Nurturance/Love (females > males) will be replicated.

5) The Mini-K, a measure of LH strategy, will be positively correlated with Nurturance/Love.

6) The Mini-K will be negatively correlated with ECR Avoidance.

7) The Mini-K will not be correlated with the Anxious Construct of the ECR.

To date, one study has attempted to find relationships between attachment in adulthood and personality as measured by the IAS-R-B5. Gallo, Smith and Ruiz (2003) explored relationships between the Adult Attachment Scale (Collins \& Read, 1990) and the IAS-R-B5 (Trapnell \& Wiggins, 1990). They found that for both sexes, both Anxious Attachment and Avoidant Attachment as measured by the AAS correlated positively with Neuroticism ( $r$ ranging between 0.29 and 0.44). Both Anxious Attachment and Avoidant Attachment were also negatively associated with Dominance/Power for both sexes ( $r$ ranging between -0.23 and -0.35 ). For both sexes, Avoidant Attachment was negatively associated with Affiliation, labeled Nurturance/Love in the present study (for men, $r=-0.34$; for women, $r=-0.36$ ); women's Anxious Attachment, but not men's, was significantly correlated with Affiliation $(r=-0.20)$.

These findings do not conform well to the hypotheses of the present study. However, a major difference between this study and the present study is the use of the ECR rather than the AAS. The ECR has become a standard measure in the area of adult attachment.

To examine how LH strategy correlates with Nurturance/Love and attachment Trust, we created two separate operationalizations of the K-Factor, which is the construct specified in the Arizona Life History Battery (ALHB; Figueredo, 2007). The ALHB is a complication of eight scales, one of which is the Experiences in Close Relationships Scale. The first operationalization, which we simply called K-Factor included both constructs of the ECR: Anxious and Avoidant. The second operationalization, which we called K-Alternative, includes only the avoidant construct of the ECR attachment. We specified these two constructs as such due to the theoretical reasons stated above. As noted, Avoidant Attachment is hypothesized to be the reverse of Nurturance/Love. Anxious Attachment, however, reflects more a lack of Trust, and not a deficit in one's ability to love.

\section{Materials and Methods}

\subsection{Subjects}

A total of 635 subjects were recruited from upper-division psychology classes at an ethnically diverse urban West coast university over four years, 2004-2007. The 2004-2006 merged sample was $80 \%$ female. Seventy-two percent of the 2004-2006 sample was between the ages of 19 and 23, ranging from 19 - 60. The 2007 sample was 78\% female, and 70\% percent of the sample was between 19 and 23, ranging from 19 - 62. Ethnicity distribution was 34\% White, 36\% Hispanic, 10\% Asian, 8\% African American, and 12\% other or refused to identify.

\subsection{Procedures}

Participants in all samples were recruited as volunteers during university classes; individuals completed the entire series of self-report measures in paper-and-pencil format to permit classroom-based administration. Participants were debriefed in person immediately after everyone completed their packets.

\subsection{Measures}

All subjects were given the IAS-R-B5 as part of a larger battery of measures, including the Mini-K (Figueredo et al., 2006), which is a short form of the ALHB and may be used in its place. In the first three years of the study, subjects $(N=424)$ were given the original version of the ECR (Brennan, Clark, \& Shaver, 1998). In 2007, the 
subjects $(N=211)$ were given the revised version of the ECR-R (Fraley, Waller, \& Brennan, 2000).

The Mini-K Short Form (Figueredo et al., 2006) measures life history strategy in general. The Mini-K consists of 20 items and correlates highly with the $A L H B$ (the average correlation in a recent meta-analysis was 0.75 , and the disattenuated population value $(\rho)$ for this was 0.91; Figueredo, Wolf, Olderbak, Gladden, Fernandes, Wenner et al., 2014). The scale measures LH indicators such as familial closeness and risk avoidance rated on a 7-point Likert scale $(-3=$ strongly disagree; $+3=$ strongly agree; $\alpha=0.74)$.

Interpersonal Adjective Scale-Revised Big Five (Trapnell \& Wiggins, 1990). The IAS-R-B5 scale is based on the Interpersonal Circle, which has two axes (Nurturance/Love and Dominance/Power) that cover the same factor space as Extraversion and Agreeableness in standard personality scales. The scale also includes standard items measuring the other three dimensions of the Big Five-Neuroticism, Conscientiousness, and Openness. Research on the Interpersonal Circle indicates that the Nurturance/Love dimension involves the tendency to provide aid for those needing help, including children and people who are ill (Wiggins \& Broughton, 1985), and would therefore be expected to be associated with ideal child-nurturing behaviors. This dimension is strongly associated with measures of femininity, and is associated with warm, empathic personal relationships and dependence (Wiggins \& Broughton, 1985), traits that would reliably be found in a slow life history strategist. Indeed, previous research indicates that women score higher on the IAS-R-B5 Nurturance/Love scale by a very robust 0.88 standard deviations (Trapnell \& Wiggins, 1990; 2004-2006 sample: $\alpha_{\text {Dominance/Power }}=0.75, \alpha_{\text {Neuroticism }}$ $=0.76, \alpha_{\text {Nurturance/Love }}=0.89, \alpha_{\text {Conscientiousness }}=0.88, \alpha_{\text {Openness }}=0.85 ; 2007$ sample: $\alpha_{\text {Dominance/Power }}=0.83, \alpha_{\text {Neuroticism }}$ $=0.90, \alpha_{\text {Nurturance/Love }}=0.88, \alpha_{\text {Openness }}=0.88$, and $\left.\alpha_{\text {Conscientiousness }}=0.925\right)$.

Experiences in Close Relationships (Brennan, Clark, \& Shaver, 1998; Fraley, Waller \& Brennan, 2000). We used two different versions of the Experiences in Close Relationships Inventory. Intuitively, the Anxiety construct, as measured by the ECR, appears to be a fairly straightforward measure of Trust conceptualized paradigmatically as fear of abandonment. Typical items include: "I worry about being abandoned"; "I worry a fair amount about losing my partner"; "I worry about being alone”. It is thus conceptually linked to attachment as a protection system motivated by fear of abandonment. The attachment perspective states that insecurely attached children have formed an insecure internal working model in which others cannot be relied on based on their experiences with attachment figures in infancy.

The Avoidance construct, as measured by the ECR, measures the extent to which people are attracted to close relationships for their own sake and is thus conceptually linked to the Nurturance/Love system. Typical items are: "I prefer not to show a partner how I feel deep down"; "I am very uncomfortable being close to romantic partners"; "Just when my romantic partner starts to get close to me I find myself pulling away"; "I try to avoid getting too close to my partner". Avoidance is thus conceptually linked with interpersonal warmth that has been proposed as constituting an independent dimension of close relationships (MacDonald, 1992; 2004-2006 sample: $\alpha_{\text {Avoidance }}=0.90, \alpha_{\text {Anxiety }}=0.89 ; 2007$ sample: $\alpha_{\text {Avoidance }}=0.92, \alpha_{\text {Anxiety }}=0.91$ ).

\subsection{Statistical Analysis}

SAS 9.1.3 software (SAS Institute, 2005) was used to perform the statistical analyses. Using PROC STANDARD and DATA, unit-weighted composite scores were estimated by computing the means of the standardized scores for all non-missing items on each scale (Figueredo, McKnight, McKnight, \& Sidani, 2000; Gorsuch, 1983). PROC CORR was used to estimate both the Cronbach's alphas and the covariance matrices among the scales. PROC GLM was used to estimate all multiple regression and analysis of variance models.

\section{Results}

\subsection{Study 1: 2004-2006 Merged Sample}

The results were in line with our predictions. That is, ECR-Anxiety had a significantly positive association with Neuroticism, but was not significantly related to IAS-R-B5 Nurturance/Love or any other personality scale. Moreover, while IAS-R-B5 Nurturance/Love was not associated with ECR-Anxiety, there was a strong negative correlation between ECR-Avoidance and IAS-R-B5 Nurturance/Love. ECR-Avoidance was not related to Neuroticism but it was negatively correlated to IAS-R-B5 Dominance/Power, Conscientiousness, and Openness. Table 2 also displays the raw Pearson bivariate correlations as well as the Pearson bivariate correlations disattenuated for scale unreliability (in parentheses). 
Table 2. Correlations between ECR Anxiety and avoidance with IAS-R-B5 measures, 2004-2006 merged samples.

\begin{tabular}{ccccccc}
\hline & ECR-Avoidance & $\begin{array}{c}\text { IAS-R-B5 } \\
\text { Nurturance }\end{array}$ & $\begin{array}{c}\text { IAS-R-B5 } \\
\text { Neuroticism }\end{array}$ & $\begin{array}{c}\text { IAS-R-B5 } \\
\text { Dominance }\end{array}$ & $\begin{array}{c}\text { IAS-R-B5 } \\
\text { Conscientiousness }\end{array}$ & $\begin{array}{c}\text { IAS-R-B5 } \\
\text { Openness }\end{array}$ \\
\hline \multirow{2}{*}{ ECR-Anxiety } & $0.161^{*}$ & -0.090 & $0.301^{*}$ & -0.113 & -0.152 & -0.046 \\
& $\left(0.200^{*}\right)$ & $(-0.113)$ & $\left(0.449^{*}\right)$ & $(-0.169)$ & $(-0.193)$ & $(-0.061)$ \\
ECR-Avoidance & & $-0.633^{*}$ & -0.055 & $-0.364^{*}$ & $-0.623^{*}$ & $-0.538^{*}$ \\
& & $\left(-0.824^{*}\right)$ & $(-0.081)$ & $\left(-0.536^{*}\right)$ & $\left(-0.782^{*}\right)$ & $\left(-0.705^{*}\right)$ \\
\hline
\end{tabular}

${ }^{*} p<0.05$.

Sex differences were also in line with our predictions. Females were higher than males on IAS-R-B5 Nurturance/Love $\left(F_{1,379}=4.35, p=0.038\right)$, while there was a trend for males to be higher than females on IAS-R-B5 Dominance/Power $\left(F_{1,357}=2.72, p=0.100\right)$. No other sex differences were significant.

A regression analysis indicated that ECR-Avoidance but not ECR-Anxiety predicted IAS-R-B5 Nurturance/Love $(b=-0.67, t=-17.41, p<0.000)$. ECR-Anxiety was not statistically significant as a predictor once ECR-Avoidance was included in the model. On the other hand, ECR-Anxiety predicted IASR-B5 Neuroticism ( $b=0.32, t=6.02, p<0.000)$. ECR-Avoidance was not statistically significant as a predictor of IASR-B5 Neuroticism once ECR-Anxiety was included in the model.

\subsection{Study 2: 2007 Sample}

The results were in line with our predictions. That is, ECR-Anxiety had a significantly positive association with Neuroticism, but was not significantly related to IAS-R-B5 Nurturance/Love or any other personality scale. Moreover, while IAS-R-B5 Nurturance/Love was not associated with ECR-Anxiety, there was a significant negative correlation between ECR-Avoidance and IAS-R-B5 Nurturance/Love. ECR-Avoidance was not related to Neuroticism or to the other personality dimensions except for a significant but low correlation with Conscientiousness $(r=-0.176, p<0.05)$. Table 3 also displays the raw Pearson bivariate correlations as well as the Pearson bivariate correlations disattenuated for scale unreliability (in parentheses).

Sex differences were in line with predictions. Females were higher than males on IAS-R-B5 Nurturance/Love ( $r=0.28, p<0.001)$ and IAS-R-B5 Neuroticism $(r=0.28, p<0.001)$. No other sex differences were significant. However, as the Mini-K was also significantly higher in females than males $(r=0.25, p<0.001)$, we examined these associations when statistically controlling for the Mini-K (see Table 4 for correlations between the Mini-K and the IAS-R-B5 dimensions). When the Mini-K was entered in the Nurturance/Love model, it was a statistically significant predictor $(\beta=0.24, t=3.48, p=0.001)$, but the residual effect of being female was also still statistically significant and only very slightly reduced $(\beta=0.22, t=3.29, p=0.001)$; when the Mini-K was entered in the Neuroticism model, it was not a statistically significant predictor $(\beta=-0.01, t=-0.09, p=0.926)$, but the residual effect of being female was nonetheless statistically significant and also only very slightly reduced $(\beta=0.27, t=3.92, p=0.001)$.

A regression analysis indicated that IAS-R-B5 Nurturance/Love significantly predicted ECR-Avoidance $(\beta=$ $-0.35, t=-5.38, p<0.001)$ but not ECR-Anxiety $(\beta=-0.05, t=-0.74, p=0.463)$. Although Neuroticism had significant bivariate correlation with both ECR-Avoidance $(r=0.23, p<0.001)$ and ECR-Anxiety $(r=0.53, p<$ 0.001), Neuroticism did not significantly predict ECR-Avoidance $(\beta=0.07, t=0.92, p=0.358)$ once ECRAnxiety $(\beta=0.56, t=7.86, p<0.001)$ was entered in the regression model, whereas Neuroticism continued to significantly predict ECR-Anxiety $(\beta=0.44, t=8.19, p<0.001)$ once ECR-Avoidance $(\beta=0.42, t=7.86, p<$ 0.001 ) was entered in the regression model.

The Mini-K was negatively and significantly correlated with the Avoidant Attachment Construct $(r=-0.21, p$ $=0.002)$ of the ECR, but was not correlated with the Anxious Attachment Construct $(r=-0.05, p=0.415)$. The correlations between K-Alterative (the construct which removed Anxious Attachment) and Nurturance/Love was positive and significant $(r=0.41, p<0.0001)$ and slightly higher than the corresponding correlation of the K-Factor that included the Anxious Attachment construct $(r=0.36, p<0.0001)$. However, the minor differences identified here are probably not sufficient to warrant a recommendation for changing the scoring of the ALHB.

We believe that these results indicate the existence of a unique inverse relationship between Slow LHS and Avoidant Attachment, but less of one with Anxious Attachment. Anxious Attachment instead appears to be mostly a product of Neuroticism. 
Table 3. Correlations between ECR anxiety and avoidance with IAS-R-B5 measures, 2007 sample.

\begin{tabular}{cccccccc}
\hline & ECR-Avoidance & \multirow{2}{*}{ Mini-K } & $\begin{array}{c}\text { IAS-R-B5 } \\
\text { Nurturance }\end{array}$ & $\begin{array}{c}\text { IAS-R-B5 } \\
\text { Neuroticism }\end{array}$ & $\begin{array}{c}\text { IAS-R-B5 } \\
\text { Dominance }\end{array}$ & $\begin{array}{c}\text { IAS-R-B5 } \\
\text { Conscientiousness }\end{array}$ & $\begin{array}{c}\text { IAS-R-B5 } \\
\text { Openness }\end{array}$ \\
\hline \multirow{2}{*}{ ECR-Anxiety } & 0.281 & \multirow{2}{*}{-0.060} & 0.034 & $0.518^{*}$ & 0.017 & -0.087 & 0.072 \\
& $(0.334)$ & & $(0.042)$ & $\left(0.631^{*}\right)$ & $(0.023)$ & $(-0.103)$ & $(0.089)$ \\
ECR-Avoidance & & $-0.211^{*}$ & $-0.358^{*}$ & 0.130 & -0.09 & $-0.176^{*}$ & -0.113 \\
$\left(-0.440^{*}\right)$ & $(0.158)$ & $(-0.118)$ & $\left(-0.251^{*}\right)$ & $(-0.138)$ \\
\hline
\end{tabular}

${ }^{*} p<0.05$.

Table 4. Correlations between Mini-K with IAS-R-B5 measures, 2007 sample.

\begin{tabular}{cccccc}
\hline & Nurturance & Dominance & Neuroticism & Conscientiousness & Openness \\
\hline Mini-K & $0.290^{*}$ & 0.074 & -0.074 & $0.187^{*}$ & 0.080 \\
\hline${ }^{*} p<0.05$. & & & & &
\end{tabular}

\section{Discussion}

The results are compatible with previous results using standard measures of the Five Factor Model, but they indicate stronger associations between the ECR measures of Avoidant Attachment and personality than in previous studies. In our view, stronger associations occurred because, theoretically, the IAS-R-B5-Nurturance/Love scale is more closely associated with ECR measures of Avoidant Attachment than measures of Agreeableness and Extraversion in standard personality measures as discussed above.

The results support the theory that there are two independent systems underlying close relationships: The consistent findings in both samples were that IAS-R-B5 Nurturance/Love was significantly (negatively) associated with Avoidant Attachment but not with Anxiety as measured by the ECR and ECR-R. In both samples, ECR and ECR-R Anxiety were positively associated with Neuroticism as measured by the IAS-R-B5. Similarly, in a previous study (MacDonald, 1999a), IAS-R-B5 Nurturance/Love was negatively correlated with ECR Avoidant Attachment $(r=-0.287 ; p<0.01)$ while the correlation with Anxious Attachment was not statistically significant $(r=0.035 ; p>0.05)$.

Regarding sex differences, the present study replicated the finding that women are higher than men on IAS-R-B5 Nurturance/Love and men were higher on IAS-R-B5 Dominance/Power in both samples, although in the latter case, the results were only trends. Men attending college, however, might be more $K$-selected than men in the population at large.

The theory proposed here suggests that a good measure of Avoidant Attachment would also show sex differences, with men higher than women on such measures. In the present study, men were higher than women on ECR-R Avoidant Attachment, and the sex difference was statistically non-significant but in the same direction for the ECR Avoidant Attachment. No sex differences were found for Anxious Attachment in either study. Similarly, a previous study (MacDonald, 1999a) found sex differences for ECR Avoidant Attachment (males > females; $\left.F_{(1,237)}=3.988, p=0.047\right)$ but not for Anxious Attachment $\left(F_{1,237}=0.531, p=0.467\right)$.

We suggest that the measurement of Avoidant Attachment with the ECR instrument could be improved by making items more in line with theory - that is, by making the ECR-Avoidant Attachment items closer to or identical to the circumplex descriptors of Nurturance/Love. There is now a large amount of data indicating that close relationships depend on a physiological reward system, and there are powerful theoretical reasons to expect sex differences in this system. In the present study, one sample showed males significantly higher than females on ECR-R Avoidant Attachment, and the other sample showed that the mean difference was in the right direction. A good measurement instrument should find reliable and valid items that show strong sex differences-sex differences that reflect the reality of sex differences in human relationships and measured quite successfully by Nurturance/Love in the Interpersonal Circle.

As indicated above, one system, the Nurturance/Love system measured (inversely) by Avoidant Attachment on the ECR and by the Nurturance/Love Dimension of the IAS-R-B5, is a Reward system making close relationships pleasurable and motivating, with the result that people in close relationships "work" to maintain the relationship. Equally, high levels of Nurturance/Love can be seen as indicative of a Slow LH Strategy. For example, children in warm parent-child relationship accept higher levels of control (Holden, 1997; Holden \& 
Hawk, 2003) and are more likely to accept parental values (Kochanska \& Murray, 2000; MacDonald, 1992, 1997). These qualities are found in Slow LH individuals; high-K individuals are more likely to be rule-governed (Gladden, 2011).

The second system is a trust system measured by the Anxious Attachment dimension of the ECR, and linked to Neuroticism as measured by the IAS-R-B5. This system relates to differences in trust in the face of threat: Can I rely on specific people, prototypically the mother in infancy, in a situation of threat? This system is based on tracking of the attachment figure's behavior, resulting in an internal working model of the trustworthiness of attachment figures that is carried forward as the default expectation for whether one can expect help from significant others in threatening situations.

Given the theory and data reviewed here, ECR-Avoidant Attachment is a misnomer from an evolutionary perspective. At the functional level, the system has resulted from natural selection to enable a high-parentalinvestment, Slow LH strategy that produces high-quality offspring; at the proximate, physiological level, it is implemented via a reward/motivational system. It is a system whose function is attraction, not avoidance. We suggest, therefore that this dimension be reversed and labeled ECR-Nurturance/Love.

\section{Limitations of the Study}

The two major limitations of this study are that: 1) all measures administered were self-report questionnaires, which may suffer from some degree of self-presentation bias; and 2) all samples collected were of university students attending courses in psychology. Although self-presentation biases are always possible in personality assessment, the correlations and regressions estimated indicated that there was still sufficient interindividiual variation among participant responses to produce interpretable results, and that there appeared to be no substantial "ceiling effect" distortion of the distribution produced by socially desirable patterns of responding. Nevertheless, it remains uncertain to what degree these results might or might not generalize to a non-student population or even to non-psychology student populations.

\section{References}

Ainsworth, M. D. S. (1967). Infancy in Uganda. Baltimore: Johns Hopkins University Press.

Atzil, S., Hendler, T., \& Feldman, R. (2011). Specifying the Neurobiological Basis of Human Attachment: Brain, Hormones, and Behavior in Synchronous and Intrusive Mothers. Neuropsychopharmacology, 36, 2603-2615. http://dx.doi.org/10.1038/npp.2011.172

Bartels, A., \& Zeki, S. (2004). The Neural Correlates of Maternal and Romantic Love. Neuroimage, 21, 1155-1166. http://dx.doi.org/10.1016/j.neuroimage.2003.11.003

Bartholomew, K. (1990). Avoidance of Intimacy: An Attachment Perspective. Journal of Social and Personal Relationships, 7, 147-178. http://dx.doi.org/10.1177/0265407590072001

Bartholomew, K., \& Horowitz, L. M. (1991). Attachment Styles among Young Adults: A Test of a Four-Category Model. Journal of Personality and Social Psychology, 61, 226-244. http://dx.doi.org/10.1037/0022-3514.61.2.226

Belsky, J., Steinberg, L., \& Draper, P. (1991) Childhood Experience, Interpersonal Development, and Reproductive Strategy: An Evolutionary Theory of Socialization. Child Development, 62, 647-670. http://dx.doi.org/10.2307/1131166

Berndt, T. J. (1986). Children’s Comments about Their Friendships. In M. Perlmutter (Ed.), Minnesota Symposia in Child Development: Vol. 18. Cognitive Perspectives on Children's Social and Behavioral Development (pp. 189-212). Hillsdale, NJ: Erlbaum.

Betzig, L. L. (1986/2008). Despotism and Differential Reproduction. New York: Aldine.

Betzig, L. L. (2012). Means, Variances, and Ranges in Reproductive Success: Comparative Evidence. Evolution and Human Behavior, 33, 309-317. http://dx.doi.org/10.1016/j.evolhumbehav.2011.10.008

Bokhorst, C. L., Bakermans-Kranenburg, M. J., Pasco Fearon, R. M., van Ijzendoorn, M. H., Fonagy, P., \& Schuengel, C. (2003). The Importance of Shared Environment in Mother-Infant Attachment Security: A Behavioral Genetic Study. Child Development, 74, 1769-1782. http://dx.doi.org/10.1046/j.1467-8624.2003.00637.x

Bouchard Jr., T. J. (1996). The Genetics of Personality. In K. Blum, \& E. P. Noble (Eds.), Handbook of Psychoneurogenetics (pp. 267-290). Boca Raton, FL: CRC Press.

Bowlby, J. (1969/1982). Attachment and Loss, Vol. I, Attachment (2nd ed.). New York: Basic Books. (Original Work Published 1969)

Brennan, K. A., Clark, C. L., \& Shaver, P. R. (1998). Self-Report Measurement of Adult Attachment. In J. A. Simpson, \& W. S. Rholes (Eds.), Attachment Theory and Close Relationships (pp. 47-76). New York: Guilford Press. 
Brussoni, M. J., Lang, K., Livesley, W. J., \& Macbeth, T. M. (2000) Genetic and Environmental Influences on Adult Attachment Styles. Personal Relationships, 7, 283-89. http://dx.doi.org/10.1111/j.1475-6811.2000.tb00017.x

Buhrmester, D., \& Furman, W. (1987). The Development of Companionship and Intimacy. Child Development, 58, 1101-1113. http://dx.doi.org/10.2307/1130550

Burkett, J. P., Spiegel, L. L., Inoue, K., Murphy, A. Z., \& Young, L. J. (2011). Activation of $\mu$-Opioid Receptors in the Dorsal Striatum Is Necessary for Adult Social Attachment in Monogamous Prairie Voles. Neuropsychopharmacology, 36, 2200-2210. http://dx.doi.org/10.1038/npp.2011.117

Buss, D. M., \& Schmitt, D. P. (1993). Sexual Strategies Theory: An Evolutionary Perspective on Human Mating. Psychological Review, 100, 204-232. http://dx.doi.org/10.1037/0033-295X.100.2.204

Chapman, E., Baron-Cohen, S., Auyeung, B., Knickmeyer, R., Taylor, K., \& Hackett, G. (2006). Fetal Testosterone and Empathy: Evidence from the Empathy Quotient (EQ) and the "Reading the Mind in the Eyes" Test. Social Neuroscience, 1, 135-148. http://dx.doi.org/10.1080/17470910600992239

Clark, L. A., Watson, D., \& Mineka, S. (1994). Temperament, Personality, and the Mood and Anxiety Disorders. Journal of Abnormal Psychology, 103, 103-116. http://dx.doi.org/10.1037/0021-843X.103.1.103

Colin, V. L. (1996). Human Attachment. Philadelphia, PA: Temple University Press.

Collins, N. L., \& Read, S. J. (1990). Adult Attachment, Working Models, and Relationship Quality in Dating Couples. Journal of Personality and Social Psychology, 58, 644-663. http://dx.doi.org/10.1037/0022-3514.58.4.644

Costa, P. T., Terracciano, A., \& McCrae, R. R. (2001). Gender Differences in Personality Traits across Cultures: Robust and Surprising Findings. Journal of Personality and Social Psychology, 81, 322-331. http://dx.doi.org/10.1037/0022-3514.81.2.322

Del Giudice, M. (2009). Sex, Attachment, and the Development of Reproductive Strategies. Behavioral and Brain Sciences, 32, 1-67. http://dx.doi.org/10.1017/S0140525X09000016

Dissanayake, C., \& Crossley, S. A. (1996). Proximity and Social Behaviors in Autism: Evidence for Attachment. Journal of Child Psychology and Psychiatry, 137, 149-156. http://dx.doi.org/10.1111/j.1469-7610.1996.tb01386.x

Dixson, A. F. (2009). Primate Sexuality: Comparative Studies of the Prosimians, Monkeys, Apes, and Humans. Oxford: Oxford University Press.

Douvan, E. A., \& Adelson, J. (1966). The Adolescent Experience. New York: John Wiley.

Evans, D. E., \& Rothbart, M. K. (2007). Developing a Model for Adult Temperament. Journal of Research in Personality, 41, 868-888. http://dx.doi.org/10.1016/j.jrp.2006.11.002

Figueredo, A. J. (2007). The Arizona Life History Battery [Electronic Version]. http://www.u.arizona.edu/ ajf/alhb.html

Figueredo, A. J., McKnight, P. E., McKnight, K. M., \& Sidani, S. (2000). Multivariate Modeling of Missing Data within and across Assessment Waves. Addiction, 95, S361-S380. http://dx.doi.org/10.1046/j.1360-0443.95.11s3.6.x

Figueredo, A. J., Patch, E. A., \& Gómez-Ceballos, C. E. (2015). A Life History Approach to the Dynamics of Social Selection. In L. Welling, T. Shackelford, \& V. Zeigler-Hill (Eds.), Evolutionary Perspectives on Social Psychology (Chap. 29, pp. 363-372). New York: Springer. http://dx.doi.org/10.1007/978-3-319-12697-5 28

Figueredo, A. J., Vásquez, G., Brumbach, B. H., Schneider, S. M. R., Sefcek, J. A., Tal, I. R., Hill, D., Wenner, C. J., \& Jacobs, W. J. (2006). Consilience and Life History Theory: From Genes to Brain to Reproductive Strategy. Developmental Review, 26, 243-275. http://dx.doi.org/10.1016/j.dr.2006.02.002

Figueredo, A. J., Wolf, P. S. A., Olderbak, S. G., Gladden, P. R., Fernandes, H. B. F., Wenner, C., et al. (2014). The Psychometric Assessment of Human Life History Strategy: A Meta-Analytic Construct Validation. Evolutionary Behavioral Sciences, 8, 148-185. http://dx.doi.org/10.1037/h0099837

Figueredo, A. J., Woodley of Menie, M. A., \& Jacobs, W. J. (2015). The Evolutionary Psychology of the General Factor of Personality: A Hierarchical Life History Model. In D. M. Buss (Ed.), Handbook of Evolutionary Psychology (2nd ed.). Hoboken, NJ: Wiley. (in press)

Fraley, R. C., Waller, N. G., \& Brennan, K. A. (2000). An Item Response Theory Analysis of Self-Report Measures of Adult Attachment. Journal of Personality and Social Psychology, 78, 350-365. http://dx.doi.org/10.1037/0022-3514.78.2.350

Gallo, L. C., Smith, T. W., \& Ruiz, J. M. (2003). An Interpersonal Analysis of Adult Attachment Style: Circumplex Descriptions, Recalled Developmental Experiences, Self-Representations, and Interpersonal Functioning in Adulthood. Journal of Personality, 71, 141-181. http://dx.doi.org/10.1111/1467-6494.7102003

Geary, D. C., (2010). Male, Female: The Evolution of Human Sex Differences (2nd ed.). Washington DC: American Psychological Association.

Gladden, P. R. (2011). Rule Governed Behavior: Investigating a Structural Model of Influences on Adherence of Rules. Unpublished Doctoral Dissertation, Tucson, AZ: University of Arizona.

Gorsuch, R. L. (1983). Factor Analysis (2nd ed.). Hillsdale, NJ: Lawrence Erlbaum Associates. 
Griffin, D., \& Bartholomew, K. (1994). Metaphysics of Measurement: The Case of Adult Attachment. In K. Bartholomew, \& D. Perlman (Eds.), Advances in Personal Relationships, Vol. 5: Attachment Processes in Adulthood (pp. 17-52). London: Jessica Kingsley.

Gubernick, D. J. (1981). Parent and Infant Attachment in Mammals. In D. H. Gubernick, \& P. H. Klopfer (Eds.), Parental Care in Mammals (pp. 243-305). New York: Plenum Press. http://dx.doi.org/10.1007/978-1-4613-3150-6_7

Holden, G. W. (1997). Parents and the Dynamics of Child Rearing. Boulder, CO: Westview Press.

Holden, G. W., \& Hawk, C. K. (2003). Meta-Parenting in the Journey of Child-Rearing: A Cognitive Mechanism for Change. In L. Kucqynski (Ed.), Handbook of Dynamics of Parent-Child Relations (pp. 189-210). Thousand Oaks, CA: Sage. http://dx.doi.org/10.4135/9781452229645.n10

Hrdy, S. B. (2009). Mothers and Others: The Evolutionary Origins of Mutual Understanding. Cambridge, MA: Harvard University Press.

Hurtado, A. M., \& Hill, K. R. (1992). Paternal Effect on Offspring Survivorship among Ache and Hiwi Hunter-Gatherers: Implications for Modeling Pair-Bond Stability. In B. S. Hewlett (Ed.), Father-Child Relations: Cultural and Biosocial Contexts (pp. 31-55). Hawthorne, NY: Aldine de Gruyter.

Insel, T. R., Winslow, J. T., Wang, Z., \& Young, L. J. (1998). Oxytocin, Vasopressin, and the Neuroendocrine Basis of Pair Bond Formation. Advances in Experimental Medicine and Biology, 449, 215-224.

http://dx.doi.org/10.1007/978-1-4615-4871-3_28

Kiesler, D. J. (1983). The 1982 Interpersonal Circle: A Taxonomy for Complementarity in Human Transactions. Psychological Review, 90, 185-214. http://dx.doi.org/10.1037/0033-295X.90.3.185

Kochanska, G., \& Murray, K. T. (2000). Mother-Child Mutually Responsive Orientation and Conscience Development: From Toddler to Early School Age. Child Development, 71, 417-431. http://dx.doi.org/10.1111/1467-8624.00154

Lang-Takoc, E., \& Osterweil, Z. (1992). Separateness and Connectedness: Differences between the Genders. Sex Roles, 27, 277-289. http://dx.doi.org/10.1007/BF00289929

Last, C. G., \& Strauss, C. C. (1989). Obsessive-Compulsive Disorder in Childhood. Journal of Anxiety Disorders, 3, 295-302. http://dx.doi.org/10.1016/0887-6185(89)90020-0

LeVine, R. A., \& LeVine, S. E. (1988). Parental Strategies among the Gusii of Kenya. In R. A. LeVine, P. M. Miller, \& M. M. West (Eds.), Parental Behavior in Diverse Societies. San Francisco, CA: Jossey-Bass. http://dx.doi.org/10.1002/cd.23219884005

Lucas, R. E., Deiner, E., Grob, A., Suh, E. M., \& Shao, L. (2000). Cross-Cultural Evidence for the Fundamental Features of Extraversion. Journal of Personality and Social Psychology, 79, 452-468. http://dx.doi.org/10.1037/0022-3514.79.3.452

MacDonald, K. B. (1992). Warmth as a Developmental Construct: An Evolutionary Analysis. Child Development, 63, 753-773. http://dx.doi.org/10.2307/1131231

MacDonald, K. B. (1995). Evolution, the Five Factor Model, and Levels of Personality. Journal of Personality, 63, 525-567. http://dx.doi.org/10.1111/j.1467-6494.1995.tb00505.x

MacDonald, K. B. (1997). The Coherence of Individual Development: An Evolutionary Perspective on Children's Internalization of Parental Values. In J. Grusec, \& L. Kuczynski (Eds.), Parenting and Children's Internalization of Values: A Handbook of Contemporary Theory (pp. 362-397). New York: Wiley.

MacDonald, K. B. (1999a). Love and Security of Attachment as Two Independent Systems Underlying Intimate Relationships. Journal of Family Psychology, 13, 492-495. http://dx.doi.org/10.1037/0893-3200.13.4.492

MacDonald, K. B. (1999b). What about Sex Differences? An Adaptationist Perspective on "the Lines of Causal Influence” of Personality Systems. Commentary on "Neurobiology of the Structure of Personality: Dopamine Facilitation of Incentive Motivation and Extraversion” by R. A. Depue \& P. F. Collins. Behavioral and Brain Sciences, 22, 530-531. http://dx.doi.org/10.1017/S0140525X99352043

MacDonald, K. B. (2005). Personality, Development, and Evolution. In R. Burgess, \& K. B. MacDonald (Eds.), Evolutionary Perspectives on Human Development (2nd ed., pp. 207-242). Thousand Oaks, CA: Sage. http://dx.doi.org/10.4135/9781452233574.n8

MacDonald, K. B. (2012). Temperament and Evolution. In M. Zentner, \& R. L. Shiner (Eds.), Handbook of Temperament (pp. 273-296). New York: Guilford Press.

Main, M., \& Goldwyn, R. (1998). Adult Attachment Scoring and Classification System. Unpublished Manuscript, Berkeley, CA: University of California at Berkeley.

Mathews, G. A., Fane, B. A., Conway, G. S., Brook, C., \& Hines, M. (2009). Personality and Congenital Adrenal Hyperplasia: Possible Effects of Prenatal Androgen Exposure. Hormones and Behavior, 55, 285-291.

http://dx.doi.org/10.1016/j.yhbeh.2008.11.007 
McCrae, R. R., \& Costa, P. T. (1990). Personality in Adulthood. New York: Guilford Press.

McCrae, R. R., Costa, P. T., Terracciano, A., Parker, W. D., Mills, C. J., De Fruyt, F., \& Mervielde, I. (2002). Personality Trait Development from Age 12 to Age 18: Longitudinal, Cross-Sectional, and Cross-Cultural Analysis. Journal of Personality and Social Psychology, 83, 1456-1468. http://dx.doi.org/10.1037/0022-3514.83.6.1456

McCullagh, K. G., \& Widdowson, E. M. (1970). The Milk of the African Elephant. British Journal of Nutrition, 24, $109-117$. http://dx.doi.org/10.1079/BJN19700014

Noftle, E. E., \& Shaver, P. R. (2006). Attachment Dimensions and the Big Five Personality Traits: Associations and Comparative Ability to Predict Relationship Quality. Journal of Research in Personality, 40, 179-208. http://dx.doi.org/10.1016/j.jrp.2004.11.003

O’Connor, T. G., \& Croft, C. M. (2001). A Twin Study of Attachment in Preschool Children. Child Development, 72, 1501-1511. http://dx.doi.org/10.1111/1467-8624.00362

Panksepp, J. (1998). Affective Neuroscience: The Foundations of Human and Animal Emotions. New York: Oxford University Press.

Rothbart, M. K. (1994). Broad Dimensions of Temperament and Personality. In P. Ekman, \& R. J. Davidson (Eds.), The Nature of Emotion (pp. 337-341). New York: Oxford University Press.

Rutgers, A. H., Bakermans-Kranenburg, M. J., van Ijzendoorn, M. H., \& van Berckelaer-Onnes, I. A. (2004). Autism and Attachment: A Meta-Analytic Review. Journal of Child Psychology and Psychiatry, 45, 1123-1134. http://dx.doi.org/10.1111/j.1469-7610.2004.t01-1-00305.x

SAS Institute, (2005). SAS® 9.1.3 Language Reference: Concepts (3rd ed.). Cary, NC: SAS Institute.

Silove, D., \& Manicavasagar, V. (2001). Early Separation Anxiety and Its Relationship to Adult Anxiety Disorders. In M. Vasey, \& M. Dadds (Eds.), The Developmental Psychopathology of Anxiety (pp. 459-480). Oxford: Oxford University Press. http://dx.doi.org/10.1093/med:psych/9780195123630.003.0020

Srivastava, S., John, O. P., Gosling, S. D., \& Potter, J. (2003). Development of Personality in Early and Middle Adulthood: Set like Plaster or Persistent Change? Journal of Personality and Social Psychology, 84, 1041-1053.

http://dx.doi.org/10.1037/0022-3514.84.5.1041

Stern, D. (1977). The First Relationship. Cambridge, MA: Harvard University Press.

Torgersen, A. M., Grova, B. K., \& Sommersted, R. (2007). A Pilot Study of Attachment Patterns in Adult Twins. Attachment and Human Development, 9, 127-138. http://dx.doi.org/10.1080/14616730701349705

Trapnell, P. D., \& Wiggins, J. S. (1990). Extension of the Interpersonal Adjective Scales to Include the Big Five Dimensions of Personality. Journal of Personality and Social Psychology, 59, 781-790. http://dx.doi.org/10.1037/0022-3514.59.4.781

Tronick, E. Z. (1982). Affectivity and Sharing. In E. Z. Tronick (Ed.), Social Interchange in Infancy (pp. 1-6). Baltimore, MD: University Park Press.

Turner, B. (1981). Sex-Related Differences in Aging. In B. B. Wolman, \& G. Stricker (Eds.), Handbook of Developmental Psychology (pp. 493-512). Englewood Cliffs, NJ: Prentice Hall.

Turner, R. A., Altemus, M., Enos, T., Cooper, B., \& McGuinness, T. (1999). Preliminary Research on Plasma Oxytocin in Normal Cycling Women: Investigating Emotion and Interpersonal Distress. Psychiatry: Interpersonal and Biological Processes, 62, 97-113.

van Ijzendoorn, M. H., Rutgers, A. H., Bakermans-Kranenburg, M. J., Swinkels, S. H. N., van Daalen, E., Dietz, C., Naber, F. B. A., Buitelaar, J. K., \& van Engeland, H. (2007). Parental Sensitivity and Attachment in Children with Autism Spectrum Disorder: Comparison with Children with Mental Retardation, with Language Delays, and with Typical Development. Child Development, 78, 597-608. http://dx.doi.org/10.1111/j.1467-8624.2007.01016.x

Wiggins, J. S., \& Broughton, R. (1985). The Interpersonal Circle: A Structural Model for the Integration of Personality Research. Perspectives in Personality, 1, 1-47.

Wilson, M. A., \& Daly, M. (1985). Competitiveness, Risk Taking, and Violence: The Young Male Syndrome. Ethology and Sociobiology, 6, 59-73. http://dx.doi.org/10.1016/0162-3095(85)90041-X

Wright, P. H., \& Scanlon, M. B. (1991). Gender Role Orientation and Friendship: Some Attenuation, but Gender Differences Abound. Sex Roles, 24, 551-566. http://dx.doi.org/10.1007/BF00288413

Zerjal, T., Xue, Y., Bertorelle, G., Wells, R. S., Bao, W., Zhu, S., et al. (2003). The Genetic Legacy of the Mongols. The American Journal of Human Genetics, 72, 717-721. http://dx.doi.org/10.1086/367774 